\title{
Correction to: Occult HBV infection in the oncohematological setting
}

\author{
C. Sagnelli ${ }^{1}$ M. Macera ${ }^{2} \cdot$ M. Pisaturo ${ }^{3} \cdot$ R. Zampino ${ }^{4} \cdot$ N. Coppola $^{5} \cdot$ E. Sagnelli $^{5}$
}

Published online: 1 July 2020

○) Springer-Verlag GmbH Germany, part of Springer Nature 2020

\section{Correction to: Infection (2016) 44:575-582 \\ https://doi.org/10.1007/s15010-016-0891-1}

The original version of this article unfortunately contained a mistake. The name N. Coppola was incorrect. The corrected author list is given above.

The original article can be found online at https://doi.org/10.1007/ s15010-016-0891-1.

E. Sagnelli

evangelista.sagnelli@unina2.it; evangelistasagnelli@libero.it

1 Department of Clinical and Experimental Medicine and Surgery "F. Magrassi e A. Lanzara", Second University of Naples, 80131 Naples, Italy

2 Azienda Ospedaliera Universitaria-Second Universityof Naples, 80131 Naples, Italy

3 Division of Infectious Diseases, AORN Sant'Anna e San, Sebastiano di Caserta, 81100 Caserta, Italy

4 Department of Medical, Surgical, Neurological, Metabolic and Geriatric Sciences, Second University of Naples, 80131 Naples, Italy

5 Section of Infectious Diseases, Department of Mental Health and Public Medicine, Second University of Naples, Via:

L. Armanni 5, 80131 Naples, Italy 